\title{
POTENCIALIDADES DA AMAZÔNIA PARA A
}

\section{PALEOPARASITOLOGIA}

Daniela Leles $^{1}$ e Adauto Araújo*2

\section{RESUMO}

Uma falácia científica muitas vezes leva à falta de interesse em estudar determinadas regiões geográficas no que diz respeito a áreas específicas do conhecimento científico. Este é o caso da Paleoparasitologia na região amazônica, que pretendemos desmitificar com esta revisão. Não é incomum encontrarmos afirmações de que na Amazônia seriam raras as possibilidades de recuperação de vestígios orgânicos preservados, o que limitaria o estudo da Paleoparasitologia. Isso pelo fato de a região haver sido habitada no passado por populações pequenas, o que resultaria em pouco material para o estudo, ou em razão dos baixos índices de preservação do material. Porém, isso não é verdade, uma vez que a região apresenta grande potencial de estudo, sobretudo de vestígios ósseos, mas também do solo arqueológico. A pesquisa deste material traria ganho inestimável para a área e poderia elucidar questões acerca da origem de infecções, se no Velho ou Novo Mundo, do caminho percorrido por elas, das datações e explicações para sua entrada nas Américas. A maioria das infecções que poderiam ser pesquisadas continua presente na região e acomete a população local constituindo, em alguns casos, importantes problemas na área da saúde coletiva. É preciso alertar os pesquisadores e moradores da região que têm conhecimento da existência deste material arqueológico sobre o fato de que, com as técnicas atuais, o menor fragmento ou quantidade do material possibilita seu estudo.

DESCRITORES: Paleopatologia; história; doenças parasitárias; doenças transmissíveis; ecossistema amazônico.

\section{ABSTRACT}

The potentialities of the Amazon for paleoparasitology

Scientific fallacy may contribute to the lack of interest in studying geographic regions in a specific field of science: for example the paleoparasitological research in Amazonia, which we aim to

1. Departamento de Microbiologia e Parasitologia, Instituto Biomédico, Universidade Federal Fluminense, Brasil.

2. Laboratório de Paleoparasitologia, Escola Nacional de Saúde Pública, Fiocruz, Brasil.

Endereço para correspondência: Daniela Leles, Laboratório de Biologia Molecular de Parasitos, Departamento de Microbiologia e Parasitologia, Instituto Biomédico, Universidade Federal Fluminense, Rua Professor Hernani Melo 101, São Domingos, CEP 24210-130 Niterói, RJ, Brasil. E-mail: dleles@id.uff.br.

* In memoriam 
demystify in this review. It is usually mentioned that in the Amazon region the possibilities of recovering organic remains are very poor. The authors claim that it is due to the low population density and the high humidity that cause rapid decay of organic material, which is not entirely true. The region has a great potential, especially for the study of bones and also archaeological soil. Research on this kind of material would elucidate questions about the origin of infectious diseases, whether they come from the Old World or were autochthonous to the New World. Paleoparasitology associated with archaeological data may also contribute to the comprehension of prehistoric migration, both regarding the dates and routes followed by ancient migrants. Many of these infections are currently occurring in the Amazon region. Therefore, our goal is not just to draw attention from researchers, but also to alert the local population who know the location of these archaeological sites. Also, we would like to call attention to the importance of this study, in which small fragments are enough to obtain data of great importance.

KEY WORDS: Paleopathology; history; parasitic diseases; communicable diseases; Amazonian ecosystem.

\section{INTRODUÇÃO}

Quando um erro ou engano é repetido várias vezes, ele se torna uma verdade. Assim é para muitos estudiosos o caso da região amazônica quanto à pesquisa paleoparasitológica. A inexistência de vestígios orgânicos antigos preservados tem sido argumento comum na literatura científica para justificar a ausência de achados de determinadas doenças infecto-parasitárias do passado nesta região. A explicação para esta suposta escassez de vestígios fundamentase em duas suposições: a floresta não sustentaria economias robustas e sistemas complexos, tornando-se, portanto, habitada por pequenas populações, o que refletiria na escassez de material para estudo; as condições tafonômicas da floresta tropical úmida promoveriam rápida decomposição biótica e química no solo, resultando em pouco material biológico para estudo. Estes dois mitos receberam de Souza (46) as denominações de mito da diluição demográfica e mito da diluição biológica. Equivocadamente propagados sobre a região amazônica, eles podem inclusive estar prejudicando a pesquisa paleoparasitológica nesta região, já que muitos pesquisadores não se interessam em estudar parasitoses por meio da recuperação de vestígios de microorganismos em material antigo amazônico por acreditarem que estes inexistam.

\section{MATERIAIS DISPONÍVEIS PARA O ESTUDO PALEOPARASITOLÓGICO}

Dos mais de 20 mil sítios arqueológicos do Brasil, aproximadamente $14 \%$ estão distribuídos em nove estados que têm sub-regiões inseridas na Amazônia. Ao contrário do que se poderia supor, a maioria $(83 \%)$ data do pré-contato, embora não seja possível saber se todos estes sítios estão em área de floresta com base nas informações disponibilizadas no website do IPHAN acessadas em março de 2015.

$\mathrm{Na}$ região amazônica, o material biológico predominantemente 
disponível para a pesquisa no campo da Paleoparasitologia é encontrado nos ossos, o que permite o estudo de diversos parasitos teciduais e sanguíneos. A preservação deste material foi possível, em parte, graças aos rituais funerários realizados pela população indígena. Porém, em virtude da diversidade de rituais, em alguns casos o que permitiu a preservação também pode ter comprometido parte do material. Ainda que seja temeroso comparar ritos funerários atuais com o que teria ocorrido no passado, olhá-los pode ser essencial para entender como este material se preservou, o que nele pode ser recuperado e qual é a melhor técnica parasitológica a ser utilizada. Muitas destas práticas envolveram ações como desmontar o corpo para que os ossos pudessem ser colocados em urnas funerárias, apressar a decomposição do cadáver, queimar completa ou parcialmente e expor ao consumo de animais. Alguns ritos envolviam, entre outras práticas, um primeiro enterramento, a remoção posterior para só então o cadáver ser colocado em local definitivo (46). Várias destas urnas funerárias e ossos hoje estão depositadas em coleções de museus, universidades e outras instituições federais e estaduais brasileiras, museus fora do Brasil e também em coleções particulares, o que neste último caso dificulta a sua localização (46). Porém, muito deste material se perdeu em razão da própria cultura científica da época, visto que, nas primeiras expedições de pesquisa feitas na Amazônia, a Antropologia estava voltada para estudos da evolução humana, nos quais praticamente interessavam somente crânios inteiros e intactos, sendo o resto deixado no próprio sítio ou descartado. Em outros casos, no que tange à arqueologia funerária, o interesse estava voltado exclusivamente para a cerâmica e não era dado o devido valor ao que se encontrava dentro dela (46).

Quanto à preservação de coprólitos (fezes fossilizadas ou dessecadas), talvez os mitos sejam em parte verdadeiros e, de fato, o material não se preserve bem na região. Na coleção de Paleoparasitologia, lotada na ENSPFiocruz-RJ, das mais de 3.000 amostras, a maioria composta de coprólitos, nenhuma é proveniente da Amazônia. Contudo, talvez este mito comece a ruir, pois foram recentemente encontrados coprólitos que se preservaram em sítios arqueológicos de Porto Rico, portanto em ambiente tropical úmido (11). Pensamos ainda que um material que não tem recebido atenção e que poderia fornecer informações correlatas aos coprólitos é o solo arqueológico, algumas pesquisas têm demonstrado a potencialidade de seu estudo na Paleoparasitologia (9).

\section{OCUPAÇÃO DA REGIÃO AMAZÔNICA}

O território amazônico começou a ser ocupado pela espécie humana há pelo menos 11 mil anos. As comunidades indígenas antigas se distribuíram ao longo da cordilheira dos Andes, áreas ribeirinhas e alagadas, áreas de interflúvio ou terra firme e zonas de estuário ou litoral. Ao contrário do que ocorre atualmente, no passado as comunidades indígenas habitaram as margens dos 
grandes rios (40). No fim do Pleistoceno, a temperatura na Amazônia era $6^{\circ} \mathrm{C}$ mais baixa que a atual, porém durante o início de sua ocupação pelos humanos a temperatura era próxima da atual. A região passou por um stress climático entre 8-6 mil anos atrás quando o clima se tornou mais seco, o nível dos rios diminuiu, a floresta retraiu e, consequentemente, uma menor diversidade de recursos ficou disponível para a população, tornando-se menor o número de sítios arqueológicos desta época encontrados (40). Contudo, segundo a Teoria dos Refúgios, em localidades específicas da Amazônia, a floresta permaneceu estável, o que permitiu uma ocupação contínua do território. Talvez isso tenha possibilitado a Amazônia ser um dos grandes centros de inovação tecnológica das Américas, principalmente para a domesticação e cultivo de plantas, como a mandioca e a pupunha, até hoje muito presentes na economia de subsistência das comunidades indígenas e da população local. Nos últimos três mil anos a floresta voltou a se expandir, a umidade e a precipitação aumentaram, surgiu o que é conhecido como Terra Preta de Índio, caracterizada pela intensa atividade antrópica do solo. A análise deste tipo de solo permite supor que, em algumas regiões amazônicas, viveram comunidades indígenas com até 18 mil pessoas. Existiram na Amazônia grupos caçadores-coletores, pescadores e agricultores que, possivelmente, não viveram isolados, mantinham contato e se mobilizavam (40).

Todas estas alterações climáticas, diferentes práticas de subsistência e mobilização dos grupos indígenas podem interferir nas espécies de microorganismos recuperados ao longo destes 11 mil anos de ocupação e prover informações valiosas sobre a origem e evolução das doenças.

\section{IDEIAS SOBRE O ESTUDO PALEOPARASITOLÓGICO EM MATERIAL ARQUEOLÓGICO DA AMAZÔNIA}

Grupos de pesquisa no Brasil têm estudado material arqueológico ósseo da Amazônia para definição de haplogrupos e haplótipos humanos, mostrando ser possível a recuperação de DNA antigo deste material (43). Portanto, muito provavelmente também se possa recuperar o DNA parasitário. Deve-se ressaltar que já foi demonstrado que o DNA, mesmo em solo tropical úmido, não é totalmente degradado, tornando possível a recuperação de microorganismos (11).

Assim, o estudo de vestígios arqueológicos amazônicos, especialmente aqueles que datam do pré-contato, poderiam trazer respostas acerca da origem, evolução e dispersão de várias doenças. Essa discussão torna-se mais relevante quando o foco são aquelas que ainda ocorrem na região afetando indígenas e a população local (Quadro). 
Bactérias

A tuberculose está entre as infecções mais estudadas no material arqueológico tanto do Velho quanto do Novo Mundo e se sabe que ela já estava na América do Sul antes da colonização europeia (3). Esta hipótese ganhou força com um estudo que mostrou a grande similaridade entre o genoma da bactéria recuperada de esqueletos do Peru (1.000 anos) e a encontrada em mamíferos marinhos. O fato demonstrou a importância destes animais que, ao cruzarem o Atlântico, contribuíram em parte como fonte de infecção humana (6). Contudo, continuam a ser uma incógnita os grandes espaços em branco ou a ausência de achados do pré-contato na América do Sul, principalmente no Brasil. Segundo Coimbra Jr. (17), as explicações para este fato são frágeis e não convincentes, principalmente diante da falta de estudos com material arqueológico da Amazônia.

Embora haja mais evidências em favor de sua origem no Novo Mundo, a sífilis ainda é discutida (26). Estudos moleculares em material arqueológico não têm obtido sucesso na recuperação de seu DNA (8), exceto em situações excepcionais como a dos recém-nascidos com sífilis congênita na Espanha (século XVI-XVII) (38). Porém, sequências obtidas de material recente permitiram extrapolar cenários do passado. Indivíduos de uma comunidade indígena isolada na Guiana Francesa com lesões parecidas com framboesia, mas com particularidades atípicas, mostraram que o DNA da bactéria era mais parecido com o da sífilis venérea do que com a própria framboesia. Isso reforça a teoria de que ela já existia no Novo Mundo, que sofrera mutações ao longo dos anos e, quando chegou à Europa, já seria mais agressiva (27).

Todo parasito ou microorganismo que pode ser usado como sonda para migrações humanas será alvo de hipóteses controversas, não é diferente com Helicobater pylori (20). Supõe-se que, quando os humanos se dispersaram para fora do continente africano, já carregariam esta bactéria, sendo mais aceita uma entrada no Novo Mundo anterior à colonização europeia. Estudos em população recente da Amazônia venezuelana mostram que H. pylori estaria entre os ancestrais ameríndios há pelo menos 11 mil anos, uma vez que há similaridade entre o DNA da bactéria encontrada nesta população e o de linhagens asiáticas (23). A área forense tem demonstrado interesse na recuperação de $H$. pylori em cadáveres para auxiliar na identificação da origem geográfica destes quando grandes catástrofes naturais acontecem (39). Embora existam trabalhos de Paleoparasitologia com este microorganismo $(1,14)$, faltam estudos com material da Amazônia, os quais poderiam fomentar ou refutar algumas das hipóteses vigentes. 


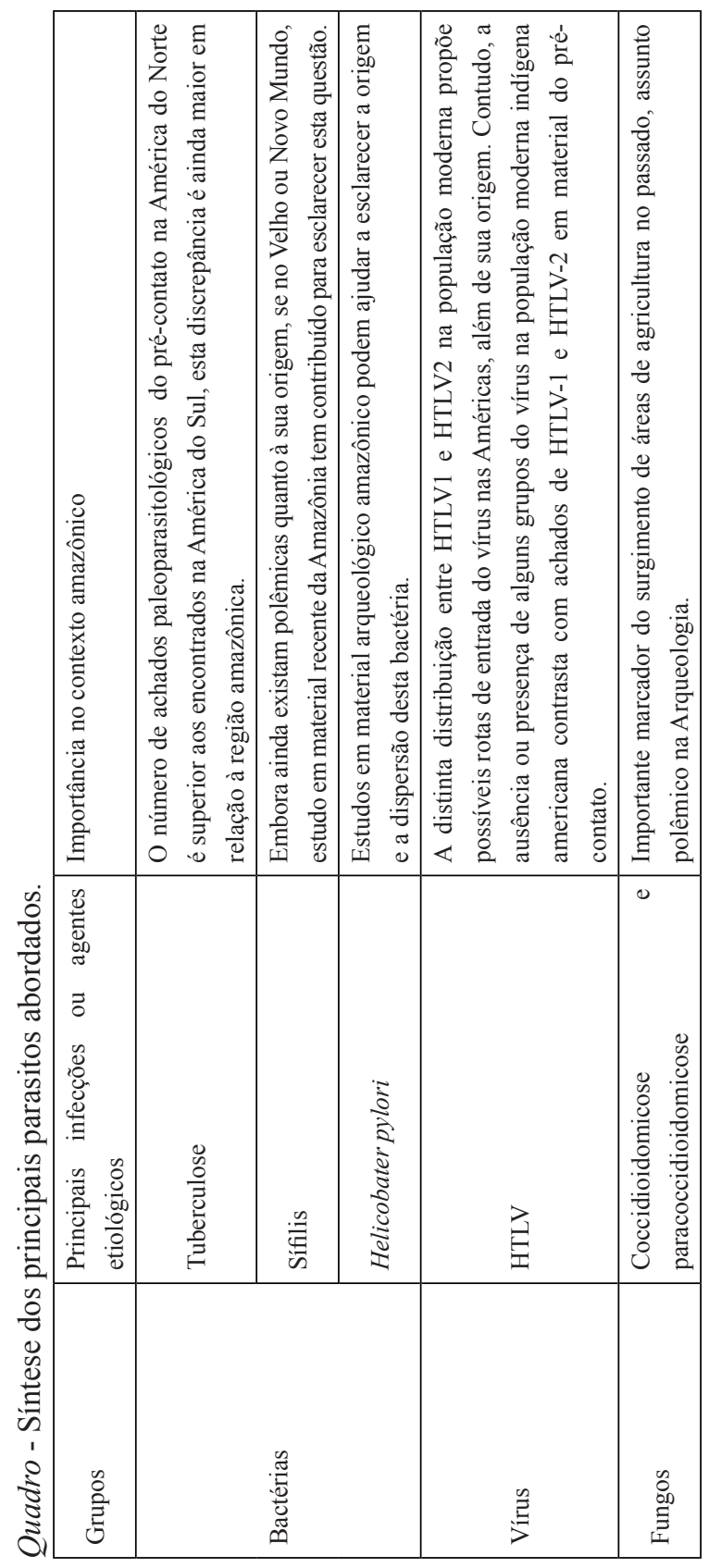




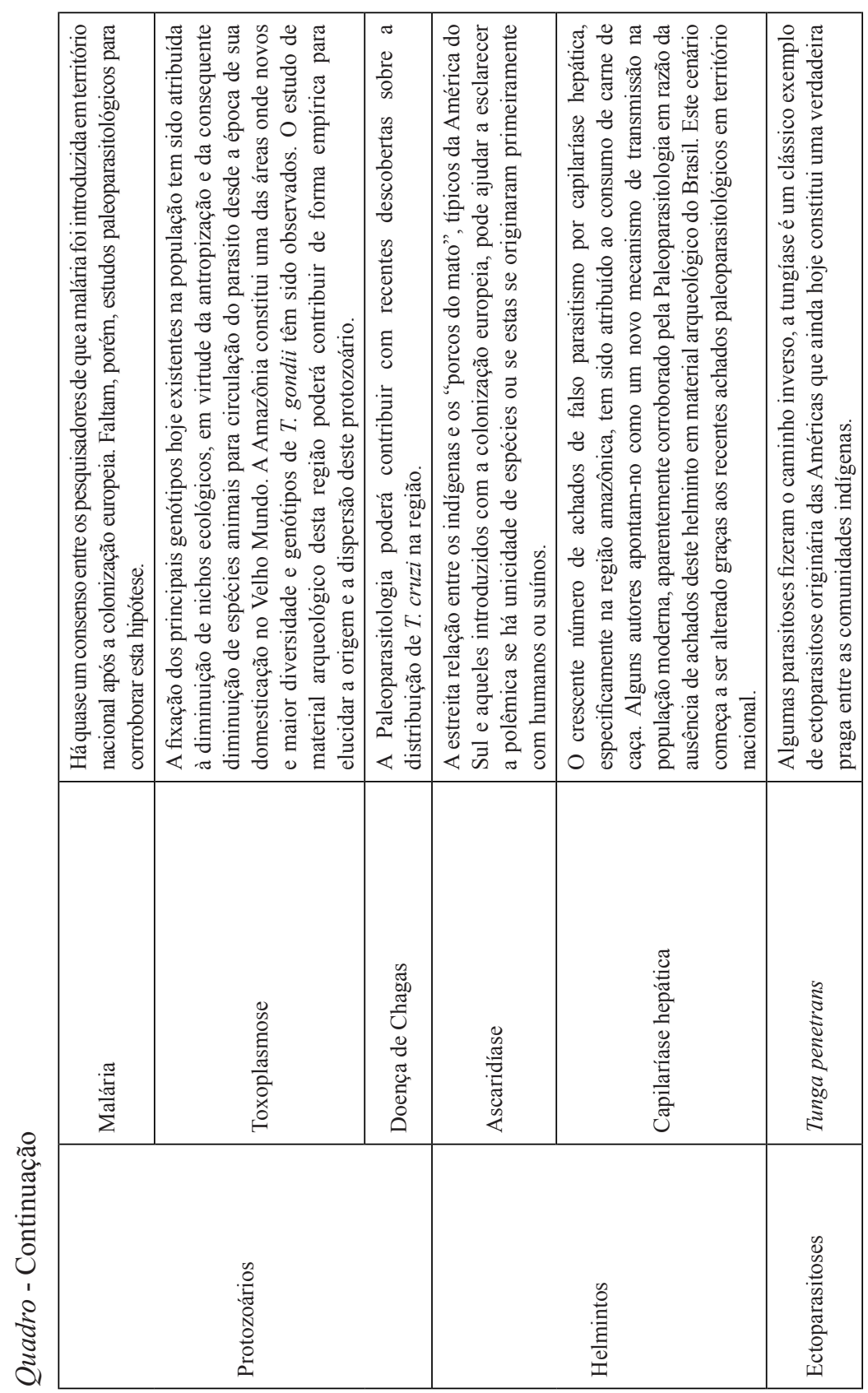


Vírus

A infecção por HTLV-1 é considerada cosmopolita, já o HTLV2 é encontrado especialmente em populações indígenas das Américas. Esta distinta distribuição levou à formulação de hipóteses do caminho percorrido pelo vírus junto com as migrações humanas. Propõe-se que, dentro do clado cosmopolita HTLV-1, as cepas ameríndias originaram-se na África, de onde se disseminaram para as Américas após a colonização junto com o comércio de escravos e migrações japonesas recentes. Já o HTLV-2 teria sido introduzido nas Américas acompanhando as primeiras migrações humanas, o que se explica por sua soroprevalência entre os grupos indígenas isolados das Américas e falta de positividade para STLV entre os macacos do Novo Mundo. Li e col. (31) recuperaram DNA do vírus HTLV-1 em uma múmia Andina datada de 1.500 anos. Na época, o trabalho foi contestado sob o argumento de que a demonstração do HTLV-1 em material humano do pré-contato estaria no caminho contrário a tudo que se supunha sobre sua origem, visto que, além de sua raridade entre os indígenas americanos, todas as endemias das Américas têm ligação com os grupos africanos e o fragmento de DNA analisado era pequeno (22). O estudo de localidades mais recentemente povoadas, como a Oceania, sugere uma entrada antiga do vírus HTLV-1 na região (13). Coulthart e cols. (19), por meio de análises estatísticas e filogenia, não rejeitaram qualquer das hipóteses para entrada de HTLV-1 no Novo Mundo, se com as primeiras migrações ou com a colonização recente do continente. Halkyer (25) pesquisou HTLV em múmias da Bolívia datadas de 3.600-900 anos, tendo detectado DNA de HTLV-1 e HTLV-2 em um indivíduo Chuquisaca e outro Tiwanaku, respectivamente. Todas estas polêmicas mostram a importância do estudo de material ósseo de ameríndios da Amazônia.

Fungos

Tem sido proposto o estudo da coccidioidomicose como marcador de áreas de agricultura no passado, pois sua presença está associada à intensa atividade antrópica no solo, como cultivo de plantas e acúmulo de contaminantes domésticos (20). Como é assunto controverso, é importante descobrir quando e onde estas áreas surgiram na Amazônia. No passado, as comunidades indígenas usavam a técnica de coivara, processo de queima da terra para seu posterior plantio, portanto temperaturas muito altas como a atingida durante este processo podem ter destruído estes microorganismos. Não se sabe ao certo se esta micose chegou ao continente americano após a colonização ou se já existia aqui entre roedores, uma vez que estes animais possuem genes de resistência à coccidioidomicose, o que poderia ser interpretado como uma maior adaptabilidade (20). Como na América do Norte há maior diversidade 
genética neste microorganismo quando se compara com a América do Sul, acredita-se que este seja mais recente no continente sul-americano. Assim, parece-nos que a análise desses fungos não somente no solo arqueológico, mas também nos vestígios ósseos de espécies de roedores exóticas e autóctones seria esclarecedora. Outra espécie de interesse é a paracoccidioidomicose, que atualmente tem elevada prevalência na Amazônia e também entre os indígenas (51). Quando oportunista, a infecção pode atingir um nível sistêmico, assim o estudo de ossos humanos antigos poderia fornecer dados sobre esta parasitose no passado.

\section{Protozoários}

Dentre as protozooses, talvez a toxoplasmose seja a mais negligenciada pela Paleoparasitologia, possivelmente por causa das peculiaridades do ciclo biológico e da consequente dificuldade de seu encontro no material antigo. Uma primeira abordagem metodológica para o seu estudo em material antigo foi proposta por meio do diagnóstico molecular com base em tecidos intencionalmente dessecados de roedores infectados com T. gondii (48). Embora o protozoário não fosse o foco da pesquisa, detectou-se pela primeira vez material genético de $T$. gondii em um estudo metagenômico com múmias egípcias (29), o que reforça as possibilidades de seu encontro em material antigo. As expansões clonais de $T$. gondii coincidem com os primeiros assentamentos humanos há 10 mil anos no Velho Mundo. Assim, a fixação de determinados genótipos na população tem sido atribuída, sobretudo, à diminuição de nichos ecológicos, fruto direto da antropização e da diminuição de espécies para a circulação do parasito (36). Novos genótipos e maior diversidade têm sido encontrados nas Américas Central e do Sul e novas hipóteses têm sido propostas para sua origem e dispersão (47). Assim, a Amazônia representa um cenário único com a presença da espécie humana, de animais domésticos e principalmente dos silvestres, em proporções não observadas em qualquer outra região do planeta.

A malária é atualmente a endemia mais importante da Amazônia e pode, em alguns anos, atingir um caráter epidêmico na região e até mesmo voltar a aparecer em regiões fora da Amazônia, como já ocorreu (37) recentemente. Alguns autores vislumbram cenários futuros em virtude das modificações climáticas que afetarão parasitos que envolvem vetores, como os do gênero Anopheles sp. (18). Os primeiros insetos transmissores de alguma forma de malária surgiram há milhões de anos e se alimentavam de animais extintos, o que pôde ser comprovado por meio de estudos em insetos preservados em âmbar (41). A malária tem sido objeto de estudo em material arqueológico de grandes personalidades da história da humanidade, por exemplo, o menino Faraó Tutankhamum e a família Medici do período renascentista italiano $(21,28)$. Todavia, embora a história seja motivo de fascínio, novamente os cientistas direcionam o questionamento para desvendar se a malária foi trazida 
para o Novo Mundo e quando isso ocorreu (50). Ao que parece, existem mais evidências a favor de uma entrada posterior à colonização: se os primeiros humanos a entrarem no Novo Mundo já estivessem com malária, seria de se esperar que nossas comunidades indígenas atuais tivessem elevada prevalência de determinadas doenças do sangue e alguma resistência, ou que Pedro Vaz de Caminha e Padre Anchieta a descrevessem em seus documentos. Na região amazônica, os sítios de Terra Preta que indicam intensa atividade antrópica pelos indígenas são bem maiores ao longo dos rios do que nos sítios interfluviais, portanto, se a malária existisse no período pré-colonial, a população teria abandonado os sítios ao longo dos rios. Alguns autores pontuam que se a maioria dos humanos chegou ao Novo Mundo pelo estreito de Bering, por causa do frio da região, esta funcionaria como um filtro para entrada da doença. Porém, também existiram rotas transoceânicas, como foi demonstrado pelo encontro de geohelmintos em coprólitos humanos datados do período précontato. Seguindo-se este raciocínio, a ponte de gelo também teria funcionado como um filtro para estes parasitos (4). Em 2005, já se ressaltava a importância de tentar recuperar e estudar material biológico arqueológico da Amazônia com foco na malária (15), mas até o momento este inexiste.

Quanto aos tripanossomatídeos, o destaque deve ser dado ao Trypanosoma cruzi. Acreditava-se que este protozoário passou a infectar humanos em território nacional com a colonização europeia em consequência das construções de casas de pau-a-pique e da domiciliação do que já foi um dos principais vetores da parasitose, o Triatoma infestans. No Brasil, a Paleoparasitologia demonstrou que este protozoário já acometia os primeiros humanos que aqui chegaram há milhares de anos e inclusive associou os achados à doença e a possíveis mecanismos de transmissão em populações pré-históricas (5). Atualmente novos modelos de distribuição do T. cruzi na região amazônica têm sido propostos pela epidemiologia molecular (32). Apesar das limitações inerentes ao trabalho com DNA antigo, a potencialidade da Paleoparasitologia em também genotipar os possíveis isolados encontrados, principalmente nos ossos antigos, pode lançar luz a estes recém-descobertos cenários.

Helmintos

Ascaris lumbricoides é conhecido como parasito de humanos e Ascaris suum, como parasito de suínos. Duas perguntas vêm sendo debatidas há pelo menos meio século: Estas são ou não a mesma espécie? E em qual destes hospedeiros este parasito se originou? (30). Embora os ascarídeos tenham surgido há milhões de anos e, surpreendentemente, mantido algumas características morfológicas como a presença de casca mamilonada nos ovos (45), as evidências mais antigas do gênero Ascaris spp. foram encontradas em uma caverna na França e o contexto arqueológico sugere datação de pelo menos 
30 mil anos (7). Como ossos de suídeos não foram encontrados na caverna e se tratava de achado anterior à domesticação destes animais, foi proposto que este geohelminto teria se originado nos humanos. Segundo Loreille e Bouchet (33), os achados de Ascaris sp. na América do Sul do período pré-contato comprovariam a origem na espécie humana, uma vez que aqui não se tinha porco domesticado, os quais só vieram com os primeiros europeus. Quando estes artigos foram produzidos só havia um achado de Ascaris sp. na América do Sul em material humano, e em um sítio arqueológico com problemas de datação, o que prejudicava a avaliação se eram do período pré-contato. Porém, por meio do diagnóstico molecular em coprólitos humanos de pelo menos 13 mil anos, foi comprovada a existência de Ascaris sp. na América do Sul em período pré-colombiano. Contudo, o achado de Ascaris em material humano do pré-contato não comprova a origem do parasito neste hospedeiro. Esta conclusão foi possível tanto com a observação de material etnográfico que mostra o estreito contato de comunidades indígenas com porcos originários das Américas (Tayassu pecari e Pecari tajacu) quanto de recentes achados do parasito nestes animais (30). Em virtude da estreita relação entre humanos e suínos domésticos e silvestres na região amazônica, o estudo não somente do material arqueológico, mas também do atual, poderia ajudar a esclarecer a origem deste helminto que continua não esclarecida.

Trichuris trichiura é um dos helmintos mais bem documentados no registro paleoparasitológico, porém, no contexto amazônico, um outro trichurídeo tem chamado a atenção: Capillaria hepatica. Em 1981, pesquisadores (16) relataram falso parasitismo em grupos indígenas Suruí de Rondônia. Após um longo período sem relatos publicados ou não publicados, novos casos de falso-parasitismo na Amazônia foram descritos recentemente. Carvalho-Costa e cols. (12) relataram um caso em uma senhora de 83 anos de idade, moradora do Alto Rio Negro. O achado foi atribuído ao fato de a senhora haver consumido carne de anta (Tapirus terrestris) na semana em que realizou o exame de fezes. Foi relatado a uma equipe de pesquisa da Fiocruz que estava em viagem de campo nesta região que os achados destes ovos nas fezes dos moradores locais não eram incomuns. Novos registros foram feitos em Rondônia e em populações ribeirinhas, neste último grupo foi possível associar alguns casos ao consumo de carne de caititu (porco do mato da região) $(10,24)$. Camargo e cols. (10) consideram que este seria um novo mecanismo de transmissão com baixa patogenenicidade e infectividade. Almeida e cols. (2) encontraram ovos de C. hepatica em fígado de paca (Agouti paca) proveniente do estado do Acre e revelaram preocupação com a dispersão destes ovos no ambiente em virtude do risco de infecção verdadeira em outros hospedeiros. Consideramos que este não é um novo mecanismo de transmissão, uma vez que ele existe desde tempos pré-históricos. Em sítios da Argentina há relatos de ovos de $C$. hepatica em coprólitos de felinos, predadores naturais de roedores, hospedeiros definitivos do parasito. O que chamava a atenção 
dos paleoparasitologistas brasileiros eram tanto os relatos atuais no Brasil quanto os achados arqueológicos na Argentina, destacando-se a falta destes em material arqueológico do Brasil. Porém, estes foram encontrados em coprólitos de felinos do Parque Serra das Confusões no estado do Piauí (44) que só recentemente têm sido analisados, o que mostra que, quando se amplia a região de estudo e o esforço de busca, os resultados aparecem.

Ectoparasitos

A pediculose tem recebido maior atenção dos pesquisadores, os quais mudaram até mesmo os rumos do que conhecíamos nos livros de História ao destacarem que algumas batalhas são ganhas ou perdidas pelas doenças. Numa cova coletiva cujos artefatos mostraram se tratar de soldados de Napoleão, surpreendentemente, foram identificados Pediculus humanus humanus aderidos aos vestígios que restaram da farda dos soldados. A espécie foi confirmada pela análise de seu DNA e uma pesquisa mais detalhada mostrou positividade para Bartonella quintana, também encontrada nos dentes de boa parte daqueles esqueletos. Em uma população imunocomprometida como certamente era aquela, pode ter causado nesses soldados a febre das trincheiras e tê-los levado ao óbito (42). A datação da separação do piolho do corpo e da cabeça por meio de análises de bioinformática também ajudou a descobrir quando as vestimentas surgiram na humanidade, passo importante para sua expansão e conquista de continentes gelados (49).

Porém, no contexto amazônico, talvez o ectoparasito mais relevante seja uma espécie de pulga, a Tunga penetrans. O nome Tunga, originário da língua Tupi, era como os indígenas denominavam esta pulga, popularmente conhecida como "bicho-de-pé, bicho-de-porco ou pulga-da-areia". Quando se faz referência à época do contato entre índios e colonizadores europeus e a subsequente mortandade dos indígenas pelas doenças, é quase inevitável pensar que as doenças só chegaram ao Novo Mundo, mas não fizeram o caminho inverso. Aqui está um dos mais clássicos e claros exemplos de uma espécie originada nas Américas. Algumas evidências convergem para esta hipótese: a) a descrição desta pulga aparece em vários relatos históricos que abordam infecções e doenças observadas nas Américas na época do contato; b) os relatos de tungíase no Velho Mundo só começaram a aparecer nas crônicas espanholas com a volta dos grandes navegadores para a Europa; c) a prova incontestável é a sua representação em cerâmicas antropomórficas pertencentes às culturas Chimu e Maranga, do Peru, que datam do pré-contato. Nestas representações são vistas as pulgas nos pés e até mesmo indivíduos segurando instrumento pontiagudo para sua remoção (34). A tungíase é uma afecção milenar que até hoje é considerada uma "praga" entre as comunidades indígenas da Amazônia. 


\section{CONCLUSÕES}

Se fosse possível colocar a história do Universo no período de um ano, o homem teria surgido no último dia e os eventos de maior impacto para a origem da maioria das doenças que acometem a espécie humana, no último minuto. Olhar para o tempo em uma escala geológica permite observar com clareza quão pouco tempo entramos na história de muitas infecções que já se encontravam em várias regiões da Terra adaptadas a ambientes específicos, seus hospedeiros e vetores. Assim, desconsiderando-se a velocidade antrópica com que tudo ocorre atualmente e as alterações que o aquecimento global pode provocar no ciclo biológico de muitas infecções parasitárias, em particular na Amazônia, a verdade é que estas infecções, em sua maioria, já existiam no passado, resistiram e continuam presentes. Os sequenciadores de nova geração e a metagenômica permitem o estudo mesmo com o menor resquício de material. Existem vários trabalhos metagenômicos em material arqueológico e até comparação de metagenomas antigos, como os de múmias egípcias, com o do homem de Saqqaq, Denisova e do Homem de Gelo (29). Talvez o mais completo, ou melhor, o mais bem documentado deles tenha sido e continua a ser o Homem de Gelo (Otzi) que viveu há 5.300 anos. Deste foram obtidas informações fantásticas como, por exemplo, sua altura $(1,59$ $\mathrm{m})$, peso (50 quilos), tempo de vida (46 anos de idade), sua última refeição e doenças (artroses, intolerância à lactose, predisposição a doenças cardíacas, parasitismo por Trichuris trichiura e por Pediculus humanus e, finalmente, infecção oportunista generalizada por Treponema denticola) (35).

Por isso, dada a raridade do material arqueológico amazônico, principalmente aquele pertencente a coleções de grandes museus, é importante que os curadores e pesquisadores destas instituições saibam que a análise do menor fragmento deste material pode ser feita sem trazer prejuízos à peça em exposição ou, na impossibilidade disso, minimizá-los ao máximo. Cabe ao governo do Brasil, onde a maior parte da Amazônia se insere, ajudar na conscientização não só dos pesquisadores, mas também da população em geral que muitas vezes é quem relata a presença de ossos e urnas funerárias na região que estão totalmente desprotegidas e das pessoas que mantêm este rico material em coleções particulares. A análise para a recuperação dos vestígios parasitários no material arqueológico da Amazônia, principalmente do solo e ossos, pode desvelar aspectos da maior relevância para a compreensão da origem e evolução de diversas doenças que ainda afligem a população local. 


\section{AGRADECIMENTOS}

Ao querido Professor Adauto, que me apresentou a Paleoparasitologia e da qual nunca mais me desvencilhei porque é contagiante trabalhar ao lado de pessoas que são apaixonadas pelo que fazem. Que bom que ainda deu tempo de escrevermos mais este artigo juntos! Fonte de Financiamento: CNPq e FAPERJ.

\section{REFERÊNCIAS}

1. Allison MJ, Bergman T, Gerszten E. Further studies on fecal parasites in antiquity. Am J Clin Pathol 112: 605-609, 1999.

2. Almeida F, Caldas R, Corrêa R, Rodrigues-Silva R, Siqueira N, Machado-Silva JR. Coinfections of the cestode Echinococcus vogeli and the nematode Calodium hepaticum in the hystricomorphic rodent Agouti paca from a forest reserve in Acre, Brazil. J Helminthology 87: 489-493, 2013.

3. Anastasiou E, Mitchell PD. Palaeopathology and genes: Investigating the genetics of infectious diseases in excavated human skeletal remains and mummies from past populations. Gene 528 : 33-40, 2013.

4. Araújo A, Jansen AM, Reinhard KJ, Ferreira LF. The paleoepidemiology of Chagas Diseases. In: Ferreira LF, Reinhard KJ and Araújo A. Foundations of Paleoparasitology. Fiocruz. Rio de Janeiro, 2014. p. 419-424.

5. Araujo A, Reinhard KJ, Ferreira LF, Gardner SL. Parasites as probes for prehistoric human migrations? Trends Parasitol 24:112-115, 2008.

6. Bos KI, Harkins KM, Herbig A, Coscolla M, Weber N, Comas I, Forrest SA, Bryant JM8, Harris SR, Schuenemann VJ, Campbell TJ, Majander K, Wilbur AK, Guichon RA, Wolfe Steadman DL, Cook DC, Niemann S, Behr MA, Zumarraga M, Bastida R, Huson D, Nieselt K, Young D, Parkhill J, Buikstra JE, Gagneux S, Stone AC, Krause J. Pre-Columbian mycobacterial genomes reveal seals as a source of New World human tuberculosis. Nature 514: 494-497, 2014.

7. Bouchet F, Baffier D, Girard M, Morel P, Paicheler JC, David F. Paléoparasitologie en contexte pléistocène: premières observations à la Grande Grotte d'Arcysur-Cure (Yonne), France. CR Acad Sci Paris 319: 147-151, 1996.

8. Bouwman AS, Brown TA. The limits of biomolecular palaeopathology: ancient DNA cannot be used to study venereal syphilis. J Archaeol Sci 32: 703-713, 2005.

9. Camacho M, Pessanha T, Leles D, Dutra JM, Silva R, Souza SM, Araujo A. Lutz's spontaneous sedimentation technique and the paleoparasitological analysis of sambaqui (shell mound) sediments. Mem Inst Oswaldo Cruz 108:155-159, 2013.

10. Camargo LMA, Camargo JSAA, Vera LJS, di Tarique CBP, Tourinho EK, de Souza MM. Capillariaisis (Trichurida, Trichinellidae, Capillaria hepatica) in the Brazilian Amazon: low pathogenicity, low infectivity and a novel mode of transmission. Parasites \& Vectors 3: 11, 2010.

11. Cano RJ, Rivera-Perez J, Toranzos GA, Santiago-Rodriguez TM, Narganes-Storde YM, Chanlatte-Baik L, García-Roldán E, Bunkley-Williams L, Massey SE. Paleomicrobiology: revealing fecal microbiomes of ancient indigenous cultures. PLoS One 9: e106833, 2014.

12. Carvalho-Costa FA, Silva AG, Souza AH, Moreira CJ, de Souza DL, Valverde JG, Jaeger LH, Martins PP, de Meneses VF, Araújo A, Bóia MN. Pseudoparasitism by Calodium hepaticum (syn. Capillaria hepatica; Hepaticola hepatica) in the Negro River, Brazilian Amazon. Trans $R$ Soc Trop Med Hyg 103: 1071-1073, 2009. 
13. Cassar O, Einsiedel L, Afonso PV, Gessain A. Human T-Cell Lymphotropic Virus Type 1 Subtype C Molecular Variants among Indigenous Australians: New Insights into the Molecular Epidemiology of HTLV-1 in Australo-Melanesia. PLoS Negl Trop Dis 7: e2418, 2013.

14. Castillo-Rojas G, Cerbón MA, López-Vidal Y. Presence of Helicobacter pylori in a Mexican Pre-Columbian Mummy. BMC Microbiology 8: 119, 2008.

15. Castro MC, Singer BH. Was malaria present in the Amazon before the European conquest? Available evidence and future research agenda. J Archaeol Sci 32: 337-340, 2005.

16. Coimbra Jr. CEA, Mello DA. Enteroparasitas e Capillaria sp. entre o grupo Suruí, Parque Indígena Aripuanã, Rondônia. Mem Inst Oswaldo Cruz 76: 299-302, 1981.

17. Coimbra Jr, CEA. Book Review [The Bioarchaeology of tuberculosis: a global view on a reemerging disease". Roberts CA, Buikstra JE. Gainesville: University Press of Florida, 2003. 343 pp.] Cad Saúde Pública 23: 977-983, 2007.

18. Confalonieri UEC, Margonari C, Quintão AF. Environmental change and the dynamics of parasitic diseases in the Amazon. Acta Tropica 129: 33-41, 2014.

19. Coulthart MB, Posada D, Crandall KA, Dekaban GA. On the phylogenetic placement of human T cell leukemia virus type 1 sequences associated with an Andean mummy. Infect Genet Evol 6: 91-96, 2006.

20. Darling M, Donoghue HD. Insights from paleomicrobiology into the indigenous peoples of pre-colonial America. A Review. Mem Inst Oswaldo Cruz 109: 131-139, 2014.

21. Fornaciari G, Giuffra V, Ferroglio E, Gino S, Bianucci R. Plasmodium falciparum immunodetection in bone remains of members of the Renaissance Medici family (Florence, Italy, sixteenth century). Trans R Soc Trop Med Hyg 104: 583-587, 2010.

22. Gessain A, Pecon-Slattery J, Meertens L, Mahieux R. Origins of HTLV-1 in South America. Nat Med 6: 232-233, 2000.

23. Ghose C, Perez-Perez GI, Dominguez-Bello MG, Pride DT, Bravi CM, Blaser MJ. East Asian genotypes of Helicobacter pylori strains in Amerindians provide evidence for its ancient human carriage. Proc Natl Acad Sci USA 99: 15107-15111, 2002.

24. Gonçalves AQ, Ascaso C, Santos I, Serra PT, Julião GR, Orlandi PP. Calodium hepaticum: Household Clustering Transmission and the Finding of a Source of Human Spurious Infection in a Community of the Amazon Region. PLoS Negl Trop Dis 6: e1943, 2012.

25. Halkyer NCO. Paleogenética de populações pré-colombianas da Bolívia: Análises do mtDNA humano, e infecções por Trypanosoma cruzi e vírus linfotrópico das células T humanas (HTLV). Rio de Janeiro [Dissertação de Mestrado em Biologia Parasitária-IOC/Fiocruz], 2008.

26. Harper KN, Zuckerman MK, Harper ML, Kingston JD, Armelagos GJ. The Origin and Antiquity of Syphilis Revisited: An Appraisal of Old World Pre-Columbian Evidence for Treponemal Infection. Am J Phys Anthropol 146: 99-133, 2011.

27. Harper KN, Ocampo PS, Steiner BM, George RW, Silverman MS, Bolotin S, Pillay A, Saunders $\mathrm{NJ}$, Armelagos GJ. On the origin of the treponematoses: a phylogenetic approach. PLoS Negl Trop Dis 2: e148, 2008.

28. Hawass Z, Gad YZ, Ismail S, Khairat R, Fathalla D, Hasan N, Ahmed A, Elleithy H, Ball M, Gaballah F, Wasef S, Fateen M, Amer H, Gostner P, Selim A, Zink A, Pusch CM. Ancestry and pathology in King Tutankhamun's family. JAMA 303: 638-647, 2010.

29. Khairat R, Ball M, Chang C, Bianucci R, Nerlich AG, Trautmann M, Ismail S, Shanab GM, Karim AM, Gad YZ, Pusch CM. First insights into the metagenome of Egyptian mummies using next-generation sequencing. J Appl Genetics 54: 309-325, 2013.

30. Leles D, Gardner SL, Reinhard K, Mayo A, Araujo A. Are Ascaris lumbricoides and Ascaris suum a single species? Parasites \& Vectors 5: 42, 2012.

31. Li HC, Fujiyoshi T, Lou H, Yashiki S, Sonoda S, Cartier L, Nunez L, Munoz I, Horai S, Tajima $\mathrm{K}$. The presence of ancient human T-cell lymphotropic virus type I provirus DNA in an Andean mummy. Nat Med 5: 1428-1432, 1999.

32. Lima VS, Xavier SC, Maldonado IF, Roque AL1, Vicente AC, Jansen AM. Expanding the knowledge of the geographic distribution of Trypanosoma cruzi TcII and TcV/TcVI genotypes 
in the Brazilian Amazon. PLoS One 9: e116137, 2014.

33. Loreille $\mathrm{O}$, Bouchet $\mathrm{F}$. Evolution of ascariasis in human and pigs: a multi-disciplinary approach. Mem Inst Oswaldo Cruz 98: 39-46, 2003.

34. Maco V, Tantaleán M, Gotuzzo E. Evidence of tungiasis in pre-Hispanic America. Emerg Infect Dis 17: 855-862, 2011.

35. Maixner F, Thomma A, Cipollini G, Widder S, Rattei T, Zink A. Metagenomic Analysis Reveals Presence of Treponema denticola in a Tissue Biopsy of the Iceman. PLoS One 9: e99994, 2014.

36. Mercier A, Ajzenberg D, Devillard S, Demar MP, de Thoisy B, Bonnabau H, Collinet F, Boukhari R, Blanchet D, Simon S, Carme B, Dardé ML. Human impact on genetic diversity of Toxoplasma gondii: Example of the anthropized environment from French Guiana Infection. Infect Genet Evol 11: 1378-1387, 2011.

37. Miguel RB, Peiter PC, Albuquerque H, Coura JR, Moza PG, Costa AD, Brasil P, Suárez-Mutis MC. Malaria in the state of Rio de Janeiro, Brazil, an Atlantic Forest area: an assessment using the health surveillance service. Mem Inst Oswaldo Cruz 109: 634-640, 2014.

38. Montiel R, Solórzano E, Díaz N, Álvarez-Sandoval BA, González-Ruiz M, Cañadas MP, Simões N, Isidro A, Malgosa A. Neonate Human Remains: A Window of Opportunity to the Molecular Study of Ancient Syphilis. PLoS One 7: e36371, 2012.

39. Nagasawa S, Motani-Saitoh H, Inoue H, Iwase H. Geographic diversity of Helicobacter pylori in cadavers: forensic estimation of geographical origin. Forensic Sci Int 229: 7-12, 2013.

40. Neves EG. Arqueologia da Amazônia; Coleção Descobrindo o Brasil. Zahar. Rio de Janeiro, 2006.

41. Poinar Jr.G. Plasmodium dominicana n. sp. (Plasmodiidae: Haemospororida) from Tertiary Dominican amber. Systematic Parasitology 61: 47-52, 2005.

42. Raoult D, Dutour O, Houhamdi L, Jankauskas R, Fournier PE, Ardagna Y, Drancourt M, Signoli M, La VD, Macia Y, Aboudharam G. Evidence for louse-transmitted diseases in soldiers of Napoleon's Grand Army in Vilnius. J Infect Dis 193:112-120, 2006.

43. Santos AKCR, Leite DS, Santos SEB. DNA mitocondrial de populações humanas précolombianas da Amazonia e as interações do passado (paleogenética). In: Pereira E, Guarapindaia V. Arqueologia Amazônica v1. MPEG, IPHAN, SECULT. Belém, 2010. p. 447468.

44. Sianto L, Souza MV, Chame M, da Luz M de F, Guidon N, Pessis AM, Araújo A. Helminths in feline coprolites up to 9000 years in the Brazilian Northeast. Parasitology International 63: 851-857, 2014.

45. Silva PA, Borba VH, Dutra J, Leles D, da-Rosa AA, Ferreira LF, Araujo A. A new ascarid species in cynodont coprolite dated of 240 million years. Anais da Academia Brasileira de Ciências 86: 265-270, 2014.

46. Souza SMFM. O silêncio biolarqueológico da Amazônia - entre o mito da diluição demográfica e o da diluição biológica na floresta tropical. In: Pereira E \& Guarapindaia V. Arqueologia Amazônica v1. MPEG, IPHAN, SECULT. Belém, 2010. p. 424-446.

47. Shwab K, Zhu X, Majumdar D, Pena HF, Gennari SM, Dubey JP, Su C. Geographical patterns of Toxoplasma gondii genetic diversity revealed by multilocus PCR-RFLP genotyping. Parasitology 141: 453-461, 2014.

48. Terra M, Bello A, Bastos O, Amendoeira MR, Coelho JM, Ferreira LF, Araújo A. Detection of Toxoplasma gondii DNA by Polymerase Chain Reaction in Experimentally Desiccated Tissues. Mem Inst Oswaldo Cruz 99: 185-188, 2004.

49. Toups MA, Kitchen A, Light JE, Reed DL. Origin of clothing lice indicates early clothing use by anatomically modern humans in Africa. Mol Biol Evol 28: 29-32, 2011.

50. Ujvari SC. A história da humanidade contada pelos vírus. Contexto. São Paulo, 2008.

51. Vieira GD, Alves TC, Lima SM, Camargo LM, Sousa CM. Paracoccidioidomycosis in a western Brazilian Amazon State: clinical-epidemiologic profile and spatial distribution of the disease. Rev Soc Bras Med Trop 47: 63-68, 2013. 